\section{Measuring Elementary-aged Children's Self- efficacy and Proxy Efficacy for Gardening and Related Health Behaviors}

\author{
Karly S. Geller ${ }^{1,2,5}$, Margaret J. Melbye ${ }^{1}$, Richard R. Rosenkranz ${ }^{2}$, \\ Candice Shoemaker ${ }^{3}$, and David A. Dzewaltowski ${ }^{4}$
}

ADDITIONAL INDEX WORDs. child overweight/obesity, physical activity, fruit and vegetable consumption, factorial validity

\begin{abstract}
SumMARY. After-school garden programs may be an effective setting to reach schoolage children to promote nutritious diets and physical activity, while reducing sedentary behavior. The current analyses drew data from Project PLANTS (i.e., promoting lifelong activity and nutrition through schools), an after-school randomized controlled trial focusing on the prevention of obesity among children through garden clubs. The purpose of the current study was to evaluate the psychometric properties of a scale measuring children's self-efficacy and proxy efficacy within the after-school, gardening context. In addition to children's garden self-efficacy, measurement scales for gardening, physical activity, and fruit and vegetable proxy efficacy were also examined. Proxy efficacy was defined as children's confidence that they have the skills and abilities to get their parent to provide behavior-specific opportunities. Participants $(N=969)$ were fourth grade students ( $n=611$; age 9.4 years, $\mathrm{SD}=0.6 ; 63 \%$ white, $50 \%$ female $)$ and fifth grade students ( $n=358$; age 10.4 years, $\mathrm{SD}=0.6 ; 57 \%$ white, $54 \%$ female) attending eight elementary schools. Exploratory factor analysis (EFA) $(n=484)$, confirmatory factor analysis (CFA) $(n=485)$, multigroup invariance, and tests to examine the sensitivity in detecting expected mean differences determined scale construct and criterion validity. The measurement model included five constructs: garden selfefficacy (seven items), garden barrier self-efficacy (four items), parent-directed proxy efficacy for physical activity opportunities (six items), fruit and vegetable availability (seven items), and opportunities to garden (four items). The five-factor model fit the data well [comparative fit index $(\mathrm{CFI})=\mathbf{0 . 9 5 8}$ ], demonstrating factor determinacy coefficients $\geq 0.940$. Tests of invariance (equal form, factor loadings, and indicator intercepts) were acceptable between genders [change in CFI $(\Delta \mathrm{CFI})=$ $0.000]$, fourth and fifth graders $(\triangle \mathrm{CFI}=0.000)$, and normal and overweight/obese weight status children $(\Delta \mathrm{CFI}=\mathbf{0 . 0 0 0})$. Females had greater garden self-efficacy, garden barrier self-efficacy, garden proxy efficacy, and fruit and vegetable proxy efficacy. The current measurement model demonstrated good factorial validity, confirming the unbiased generalizability across gender, grade level, and body mass index subgroups. Further validation is suggested in additional populations and across time points.
\end{abstract}

$\mathrm{Y}$ outh obesity is a global concern and epidemic in the United States (Ogden et al., 2012), demonstrating strong association

This project was a randomized controlled trial, targeting gardening in the effort to prevent obesity among youth. This work was supported by National Research Initiative Grant no. 2007-55215-18206 from the U.S Department of Agriculture Cooperative State Research, Education, and Extension Service Human Nutrition and Obesity Program.

${ }^{1}$ Department of Kinesiology and Health, Miami University, 420 South Oak Street, Oxford, OH 45056

${ }^{2}$ Department of Human Nutrition, Kansas State University, 201 Justin Hall, Manhattan, KS 66502

${ }^{3}$ Department of Horticulture, Kansas State University, 2021 Throckmorton Plant Science Center, Manhattan, KS 66502

${ }^{4}$ Department of Kinesiology, Kansas State University, 1A Natatorium, Manhattan, KS 66502

${ }^{5}$ Corresponding author. E-mail: gellerks@miamioh.edu. with numerous negative health outcomes (Daniels, 2006) and excessive economic costs (Wang and Dietz, 2002). Obesity is a consequence of excessive energy intake and/or insufficient energy expenditure (i.e., energy imbalance), which is largely associated with modifiable behaviors like physical activity (Janssen et al., 2005), screen time (Sisson et al., 2011), and dietary patterns (Nicklas et al., 2003). Unfortunately, many children (age 6-11 years) are not performing enough physical activity (Troiano et al., 2008) or eating enough fruit and vegetables to experience the related health benefits (Guenther et al., 2006).

Scarcity of physical activity opportunities and difficulty engaging children in nutritional programs remain significant challenges for obesity prevention efforts (White House Task Force on Childhood Obesity, 2010), accelerating the expansion of promotional efforts into unique contexts and settings. For example, community gardening is a promising approach to obesity prevention and has demonstrated potential for healthy behavior promotion among schoolage youth populations (Heim et al., 2009). Research targeting children's obesity-related behaviors within the gardening context have demonstrated success in promoting increased activity levels and healthy eating. For example, implementation of a gardening program successfully increased school-age children's gardening self-efficacy (Evans et al., 2012; Poston et al., 2005), preference for fruit and vegetables (Morris and Zidenberg-Cherr, 2002; Ratcliffe et al., 2011), fruit and vegetable asking behaviors (Heim et al., 2009) and fruit and vegetable consumption (Evans et al., 2012; Langellotto and Gupta, 2012; Parmer et al., 2009; Ratcliffe et al., 2011). Additionally, garden-based programs have successfully increased children's physical activity and home gardening (Draper and Freedman, 2010). To fully optimize the promise of garden-based promotional efforts, the mechanisms mediating children's healthy behavior require better understanding.

The social cognitive theory is a predominant model guiding the promotion of healthy lifestyle behaviors like physical activity and fruit and vegetable intake (Bandura, 1986). Theoretically, youth exert control over a desired outcome by exerting direct personal agency (i.e., selfefficacy) and/or proxy agency (i.e., proxy efficacy) (Bandura, 2001). Selfefficacy is a child's confidence to reach a desired outcome, whereas proxy efficacy is mobilized through a child's confidence to successfully solicit others to act on his/her behalf. Specifically defined, proxy efficacy is one's belief he/she has the skills and/or abilities to perform behaviors that influence others to provide desired opportunities (Bandura, 2001). Previous research has demonstrated positive associations between self-efficacy and children's fruit and vegetable intake (Geller and Dzewaltowski, 2009; Perez-Lizaur et al., 2008; Sharma et al., 2005) and physical 
activity behavior (Brown et al., 2013; Lubans et al., 2008).

Specific to children's exposure to gardening, certain causal processes of behavior change (i.e., mediators) require further understanding and valid assessment, specifically, children's selfefficacy and proxy efficacy. Reminiscent of physical activity and nutritionrelated behaviors, children have specific confidence relative to gardening and are similarly dependent on adults to provide opportunities to garden (Golan and Crow, 2004). Self-efficacy and proxy efficacy measurement scales have been examined thoroughly relative to fruit and vegetable consumption and physical activity behaviors. Within after-school programs, measurement scales were documented as psychometrically sound when assessing children's self-efficacy and proxy efficacy applicable to regular physical activity (Dzewaltowski et al., 2010) and daily fruit and vegetable consumption (Geller et al., 2009; Geller and Dzewaltowski, 2010a, 2010b). Self-efficacy and proxy efficacy scales were captured as independent but correlated constructs demonstrating appropriate measurement invariance across the demographic subgroups of gender, socioeconomic status, and race (Geller and Dzewaltowski, 2010a) and across time (Geller and Dzewaltowski, 2010b). However, there has not yet been an application of similar measurement scales to children's gardening.

The current study had two primary aims. The first was to extend validation of self-efficacy and proxy efficacy measurement scales to the gardening context, including tests of factorial validity and factorial invariance. The second objective was to test for criterion validity by examining the sensitivity of measurement scales to identify subgroup mean differences. The following hypotheses were evidence based and guided by postulates of the social cognitive theory. A multidimensional scale was hypothesized, containing garden self-efficacy and three distinguished applications of children's parent-directed proxy efficacy: proxy efficacy for fruit and vegetable consumption, proxy efficacy for physical activity, and proxy efficacy for gardening. Additionally, the measurement model was expected to generalize across groups of children based on gender, grade level, and weight status. No gender differences were expected when examining parent-directed proxy efficacy for physical activity opportunities and fruit and vegetable availability, and additional examinations of subgroup mean differences were considered exploratory.

\section{Materials and methods}

The current analyses drew data from Project PLANTS, an after-school randomized controlled trial targeting overweight prevention through an after-school gardening program among elementary-age children in Kansas. All fourth and fifth grade children attending eight elementary schools in a Kansas school district were eligible for participation $(N=1439)$. Students were included in the study if their parents provided informed consent and the child assented to participate $(N=1094)$.

Project PLANTS garden club was designed to target skills (health behaviors) and efficacy (mediator behaviors) of children to make healthy lifestyle choices (gardening, physical activity, and consumption of fruits and vegetables) as an overweight prevention program (Domenghini et al., 2011; Shoemaker et al., 2013). Selfefficacy and proxy efficacy were targeted as mediating factors. A child questionnaire measured these health and mediator behaviors.

Data were collected at the beginning and the end of the school year for 2 years. During the school day, two trained research assistants administered the child survey with the aid of a prepared script. In-class time to complete the survey was $\approx 45 \mathrm{~min}$. The institutional review board at Kansas State University approved all procedures.

Survey items were guided by the social cognitive theory and previous research, targeting children's contextspecific self-efficacy and proxy efficacy. All measurement items asked participating children to respond on a sixpoint scale, ranging from 0 (not at all sure) to 5 (very sure). The self-efficacy construct was assessed with 11 items representing children's gardening self-efficacy. Children's proxy efficacy, or confidence to elicit parental support, was assessed within three situations: gardening opportunities (four items), physical activity opportunities (six items), and fruit and vegetable availability (eight items). The next sections describe each measurement scale in detail. Items for each scale are provided in Table 1. All self-efficacy items began with, "how sure are you that you can ..." and proxy efficacy items began with, "how sure are you that you can get your parents to ..."

\section{Gardening self-efficacy}

The gardening self-efficacy construct was based on Bandura's (1997) recommendations, targeting self-efficacy relative to gardening tasks and common barriers. Seven items related to specific gardening tasks and were developed previously (O'Brien and Shoemaker, 2006; Poston et al., 2005); for example, one question asked, "how sure are you that you can plant a seed that will grow into a small plant?" Through text and verbally, gardening was explained to the children as "growing and taking care of plants for their attractive flowers and for their vegetables or fruits to eat. We can garden outside in the ground and containers and inside in containers." Four additional self-efficacy items addressed gardening in the face of barriers (e.g., no matter how busy your day is, even if it is hot or cold outside). Barrierspecific items paralleled those previously developed and validated for physical activity-related self-efficacy (Dzewaltowski et al., 2010; Saunders et al., 1997).

\section{Parent-directed proxy efficacy for gardening}

Gardening proxy efficacy was measured with four items and defined as children's confidence in their skills and abilities to get their parents to provide gardening opportunities. Items were adapted from measurement scales developed in relation to children's parent-directed proxy efficacy for physical activity opportunities (Dzewaltowski et al., 2007; Ryan and Dzewaltowski, 2002). Relevant to opportunities for children's gardening, multiple types of parental action were assessed: planning, tangible support, location, and shared gardening time. An example question representing tangible support was, "help you buy seeds and/or plants for a garden." The current research was the first to examine the validity of proxy efficacy items tailored to the garden context. 


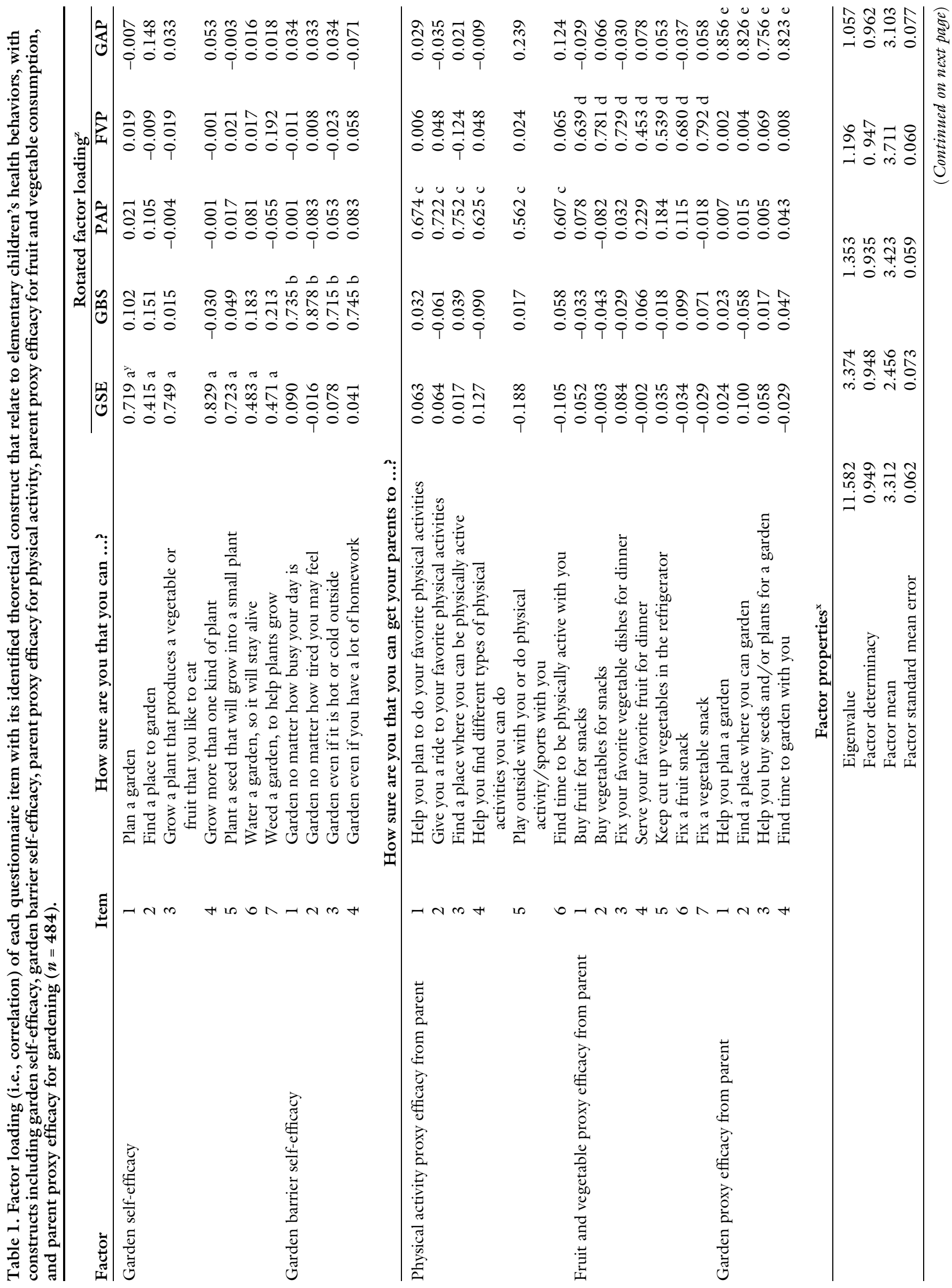




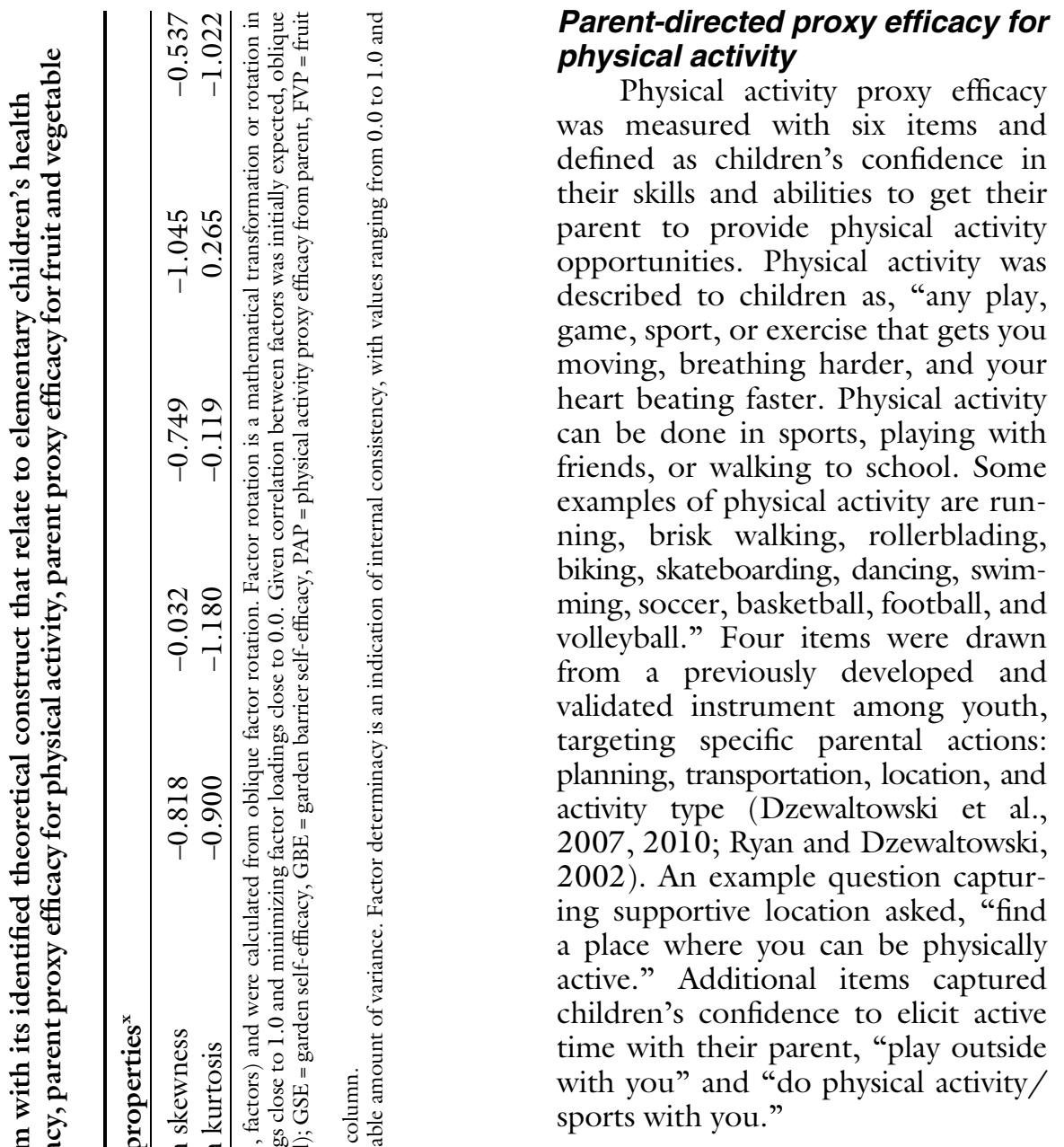

Parent-directed proxy efficacy for fruit and vegetable consumption

Eight items representing fruit and vegetable proxy efficacy were selected from previously published proxy items (Reynolds et al., 2002) and defined as children's confidence in their skills and abilities to get their parent to facilitate availability and accessibility of fruits and vegetables. Four items captured proxy efficacy related to fruit consumption, and the other four items targeted parental support for vegetable consumption. This proxy efficacy construct has been previously validated in multiple youth samples (Geller et al., 2009; Geller and Dzewaltowski, 2010a, 2010b).

Statistical analysis. Analyses evaluated the validity and reliability of self-efficacy and proxy efficacy measurement scales, including tests of factorial validity, internal consistency, multigroup invariance, and criterion validity. The final data analyzed in the current study included child responses from multiple years. Specifically, data collection occurred at the project's year 1 intervention
[2008-09 (58\%)], year 2 intervention [2009-10 (33\%)], and the 6-month follow-up [Fall $2010(9 \%)$ ]. Although data were collected from participating children at multiple time points, only their first self-report of survey questions with complete data were used $(N=969)$.

Using Mplus (version 5.21; Muthen and Muthen, Los Angeles, CA), the measurement model was examined in separate samples. The entire participant sample $(N=969)$ was divided in half randomly, and an EFA and a CFA were performed in the separated samples. In the first sample $(n=484)$, EFA analysis determined the number and manner of factors accounting for the variation/ covariation among the indicators (i.e., observed measures) (Brown, 2006). The number and pattern of factors from EFA results were then specified a priori using a CFA, which compared the hypothesized measurement model to the observed variables in the second sample $(n=485)$. Internal consistency was determined by factor determinacy coefficients that range from 0.0 to 1.0. These scores represent how accurately the factors were measured by the observed measurement items, with a value of 1.0 indicating a direct and perfect measurement. A factor determinacy coefficient of $\geq 0.80$ indicates strong correlation between observed items and the corresponding latent factor (Gorsuch, 1983).

EFA and CFA samples were then merged to maximize sample sizes for supplementary tests of measurement invariance across demographic subgroups. Measurement invariance was used to determine generalizability of the measurement model between certain groups of children, comparing boys to girls, fourth graders to fifth graders, and normal weight children to overweight/obese children. Multigroup factorial invariance was initially examined via model fit statistics, followed by nested model comparisons to test factorial invariance across selected subgroups. Before tests of model fit, subgroups were created for specific demographic variables. Given the influence of sample size on chi square value $\left(\chi^{2}\right)$ and several related statistics (e.g., SE, parameter estimates), unbalanced subgroups were equated by randomly selecting an equal number of cases from the entire sample. 
Binary subgroups were created for gender, grade level (fourth and fifth grade), and weight status (normal and overweight/obese). Missing data $(<1 \%)$ were handled with listwise deletion. Finally, tests of criterion validity examined the sensitivity of latent factors to detect subgroup differences that theoretically should exist.

\section{Factor structure and internal consistency}

The EFA procedures included principal axis factor (PAF) extraction method, followed by oblique (geo$\min$ ) rotation. Oblique rotation was used due to expected correlations among the primary structures underlying self- and proxy efficacy. The number of factors retained was determined using the following criteria: 1) factors with unrotated eigenvalues > 1.0 (Kaiser, 1961), 2) scree test (Cattell, 1966), and 3) item-tofactor loadings > 0.40 (Gorsuch, 1983). A CFA was performed within the second randomly selected sample to confirm the factor structure indicated by the EFA. In addition to $\chi^{2}$, multiple estimates were used to judge how accurately the hypothesized measurement model fit the observed items. Acceptable model fit to the data were indicated by the following goodness of fit values: CFI $\geq 0.90$ (Bentler, 1990), standardized root mean square residual $(\mathrm{SRMR}) \leq 0.08$, Tucker-Lewis index $(\mathrm{TLI}) \geq 0.95$ (Bollen, 1989), and root mean square error of approximation (RMSEA) $\leq 0.05$ with $90 \%$ confidence intervals (CIs) (Browne and Cudeck, 1993). Estimates of factor loadings, intercepts, variances, residual variances, and $\mathrm{z}$-scores were inspected for direction of association and magnitude.

\section{Multigroup factorial invariance}

The factorial invariance between specific population subgroups was determined through a sequence of CFA model comparisons. Population factorial invariance uncovers existing bias in the consistency of measurement properties across demographically determined subgroups. Suitable factorial invariance suggests associations between factor indicators (i.e., measurement items) and the factors (i.e., measurement subscales) are parallel across subgroups. An unconstrained or configural model was established, followed by tests of more restricted (nested) models to evaluate the plausibility of sequentially placed constraints. The configural model was first evaluated against observed data within each subgroup, representing the baseline model for supplementary invariance tests. Next, baseline model constraints were imposed across subgroups based on gender, grade level, and weight status to examine specific psychometric properties, which included invariance of model form, invariant factor loadings, and invariant indicator intercepts. Invariant model form indicates equality in the number of latent factors and pattern of indicator-factor loadings. Tests of invariant factor loadings and indicator intercepts establish parallel meaning and structure of latent factors across differing population subgroups. Tenability of invariance was determined based on variations between the baseline model and constrained models, specifically $\Delta \mathrm{df}$ and $\Delta \mathrm{CFI}$ $\left(\mathrm{CFI}_{\text {constrained }}\right.$ model $-\mathrm{CFI}_{\text {unconstrained }}$ model $\leq 0.01$ ) (Bollen, 1989; Cheung and Rensvold, 2002). Similar to $\chi^{2}$ statistic, $\Delta \chi^{2}$ varies in response to sample size, possibly rejecting null hypotheses when only trivial model differences exist. Previous simulation research by Cheung and Rensvold (2002) reported evidence that $\Delta \mathrm{CFI} \leq$ 0.01 is superior to $\Delta \chi^{2}$ and among the leading indexes for distinguishing outcomes of nested model constraints. Both statistics were examined, with $\Delta$ CFI operating as the final resolution.

\section{Criterion validity}

Differences in latent factor means were examined between certain subgroups via SPSS Statistics (version 21; IBM Corp., Armonk, $\mathrm{NY}$ ). Analysis of variance F test was used to test the sensitivity of each measurement scale in detecting differences between certain demographic subgroups. Mean differences in garden self-efficacy, garden barrier self-efficacy, physical activity proxy efficacy, fruit and vegetable proxy efficacy, and garden proxy efficacy were compared between groups based on gender, grade-level, and weight status. Confounding variables were initially identified via linear regression and modeled as independent variables, including school site and child ethnicity (Caucasian, nonHispanic, or ethnically diverse). Confounding effects were accounted for by calculating both unadjusted and adjusted means. Significance was set at $P$ value $<0.05$.

\section{Results}

EFA. Data used for the EFA included 484 elementary-age children with complete descriptive data and efficacy item scores. Children's mean age during the time of questionnaire completion was 9.8 years $(\mathrm{SD}=0.8)$, including fourth graders $(61.5 \%)$ and fifth graders $(39.5 \%)$. Fifty-four percent were female; $55 \%$ were Caucasian $(n=268)$ and $45 \%(n=216)$ were racially/ethnically diverse (African American, $n=56$; Asian, $n=39$; Hispanic/Latino, $n=34$; American Indian or Alaska native, $n=$ 41; native Hawaiian or other Pacific Islander, $n=5)$. The PAF analysis of the initial 29-item measurement model extracted five factors with eigenvalues greater than one that exhibited practical and theoretical reasoning. One item was dropped, due to factor loadings $<0.40$ on all identified factors. The dropped item was relevant to proxy efficacy for fruit and vegetable availability: "how sure are you that you can get your parents to keep 100\% juice in the refrigerator." All other items had factor loadings exceeding 0.40 on only one of the five emerging factors, confirming the inclusion of all 28 items. High inter-item reliability was evident, with factor determinacies ranging from 0.94 to 0.96 . Table 1 illustrates items, rotated factor loadings, factor eigenvalues, and factor determinacy coefficients.

The first factor identified garden self-efficacy, which was captured with seven items capturing children's confidence in their ability to successfully complete gardening tasks. Factor two was labeled garden barrier self-efficacy and consisted of four items identifying children's belief they can successfully garden in the face of related barriers. The final three factors targeted parentdirected proxy efficacy. The third factor identified physical activity proxy efficacy with four items, reflecting children's perception of their ability to influence their parent to provide opportunities for physical activity. Fruit and vegetable proxy efficacy was defined by seven items, representing children's confidence they can successfully request fruits and vegetables from their parent. Finally, the fifth factor was conceptualized as garden proxy efficacy or children's confidence 
in their ability to influence their parent to provide gardening opportunities.

CFA. Participants used in the CFA were 485 elementary-age children with complete descriptive data and efficacy item scores. Fifty percent of the sample were female, and at the time of self-report, children's mean age was 9.8 years $(\mathrm{SD}=0.8)$. The sample was $59.2 \%$ Caucasian and $40.8 \%$ racially/ethnically diverse (African American, $n=36$; Asian, $n=34$; Hispanic/Latino, $n=$ 39; American Indian or Alaska native, $n=31$; native Hawaiian or other Pacific Islander, $n=13$ ). Figure 1 depicts the standardized results of the specified five-factor model. The measurement model contained no double loadings. Initial model examination revealed high modification indices [MIs (>15.000)] for three constrained measurement error correlations. Measurement error represents the variance of an item that is not accounted for by its hypothesized factor. Correlated measurement error (i.e., correlated uniqueness) suggests an unmeasured relationship between two items. Following recommendations from Joreskog (1993), model modification began by freely estimating the constrained error correlation with the highest MI, then independently repeating this for each constrained error correlation in sequence of MI value. Measurement error correlations were only freed if the parameter could be interpreted substantively. Accordingly, the model was overidentified with $337 \mathrm{df}$.

FACTOR STRUCTURE AND INTERNAL CONSISTENCY. Also included in Fig. 1 are all factor loading estimates $\left(R^{2}\right)$ and standardized factor correlations. The hypothesized model fit the data well, $\chi^{2}=723.564, \mathrm{CFI}=$ $0.958, \mathrm{TLI}=0.953, \mathrm{SRMR}=0.036$, and $\mathrm{RMSEA}=0.049 ; 90 \% \mathrm{CI}=$ 0.044-0.054. All freely estimated unstandardized parameters were statistically significant (all $P<0.001$ ) and inspection of residuals indicated no ill fits within the solution $($ all $<1.96)$. As seen in Fig. 1, all factor loading estimates were strongly related to their supposed latent factors $\left(R^{2}=0.627-\right.$ $0.892)$. Finally, factor correlations were moderate (ranging from 0.415 to 0.790 ), demonstrating appropriate discriminant validity. Factor determinacies: gardening self-efficacy $=0.959$; gardening barrier self-efficacy $=0.950$; physical activity proxy efficacy $=0.942$; fruit and vegetable proxy efficacy = 0.958 ; garden proxy efficacy $=0.969$.

MULTIGROUP FACTORIAL INVARIANCE. To standardize comparisons, random samples of the larger subgroup were obtained to match the size of the subgroup with fewer participant data. Tests of invariance (equal form, factor loadings, and indicator intercepts) were acceptable between genders $(n=468$, $\Delta \chi^{2}=22.093, \Delta \mathrm{df}=23, P>0.05$; $\Delta \mathrm{CFI}=0.000)$, fourth and fifth graders $\left(n=357, \Delta \chi^{2}=21.603\right.$, $\Delta \mathrm{df}=23, P>0.05 ; \Delta \mathrm{CFI}=0.000)$, and normal weight and overweight/ obese children $\left(n=291, \Delta \chi^{2}=\right.$ $21.076, \Delta \mathrm{df}=23, P>0.05 ; \Delta \mathrm{CFI}=$ $0.000)$. For gender, all freely estimated factor loadings were statistically significant (all $P<0.001$ ) and salient $\left(R^{2}=0.591-0.889\right)$, which also resulted for both fourth and fifth grade subgroups $\left(R^{2}=0.601-0.880\right)$ and weight status subgroups $\left(R^{2}=0.583\right.$ $0.910)$. There were no remarkable points of strain noted in any of the examined models, supporting the consistent structure of baseline model across each child subgroup. Table 2 provides $\chi^{2}$ values and fit statistics for invariance testing across the specified demographic subgroups. Model one analyzed factor structure equality (equal form); each subgroup sample fit the data appropriately, serving as the baseline model for subsequent tests of invariance. Nested models were then used to examine consistency of factor loadings and indicator variances (model two); good fit to the data were established within each subgroup, verifying equivalent structure and meaning of measurement scales across the gender, grade, and weight status subgroups examined.

Criterion validity. The EFA and CFA samples were merged for tests of criterion validity. The total sample $(N=969)$ had $52 \%$ female, with a mean age of 9.8 years ( $\mathrm{SD}=$ 0.8 ). Participants were $66 \%$ Caucasian, 10\% African American, 7.5\% Asian, 7.5\% Hispanic/Latino, 7\% American Indian or Alaska native, and $2 \%$ native Hawaiian or other Pacific Islander. Table 3 reports the ability of the measure to distinguish factor mean differences between certain demographic groups. The mean and SE for each self-efficacy and proxy efficacy construct are depicted, with comparisons between populations subgroups based on gender, grade level, and weight status. The only significant covariate included in all adjusted models was ethnicity (i.e., dichotomized as Caucasian or ethnically diverse). Multiple gender-based mean differences were revealed within the adjusted model. Compared with their male counterparts, females demonstrated significantly greater levels of garden self-efficacy [mean difference $(\mathrm{MD})=0.522, P<0.001$, partial eta squared $\left.\left(\eta_{\mathrm{p}}{ }^{2}\right)=0.029\right]$ and garden barrier self-efficacy $(\mathrm{MD}=0.532, P<$ $\left.0.001, \eta_{\mathrm{p}}{ }^{2}=0.022\right)$. Females also demonstrated higher parent-directed proxy efficacy for fruit and vegetable consumption $(\mathrm{MD}=0.425, P<$ $\left.0.001, \eta_{\mathrm{p}}^{2}=0.020\right)$ and garden proxy efficacy $(\mathrm{MD}=0.658, P<$ $\left.0.001, \eta_{\mathrm{p}}^{2}=0.029\right)$.

\section{Discussion}

The final measurement model included five valid and reliable constructs with measurement invariance across child gender, grade level, and weight status, and the factor scores of these scales demonstrated multiple differences between males and females. Results supported the general hypothesis that selfefficacy and proxy efficacy are separate but related constructs within contexts related to gardening, physical activity, and fruit and vegetable consumption. Corresponding with social cognitive theory, findings suggest self-efficacy and proxy efficacy are based on distinct skills and abilities (Bandura, 2001). The final 28-item questionnaire contained two garden-related self-efficacy subscales and three parent-targeted proxy efficacy subscales. The reported measurement model demonstrated appropriate factorial validity and reliability among elementary-age youth, as well as appropriate criterion validity. Specifically, criterion validity examinations illuminated mean differences based on gender. Study results are reviewed in comparison with study hypotheses below.

First, children's garden selfefficacy diverged into two separate and valid subscales: one task-related self-efficacy and the other relating to children's self-efficacy in the face of gardening specific barriers. Such a distinction corroborates with research targeting similar behaviors, such as physical activity and fruit and vegetable consumption. In a review relevant 


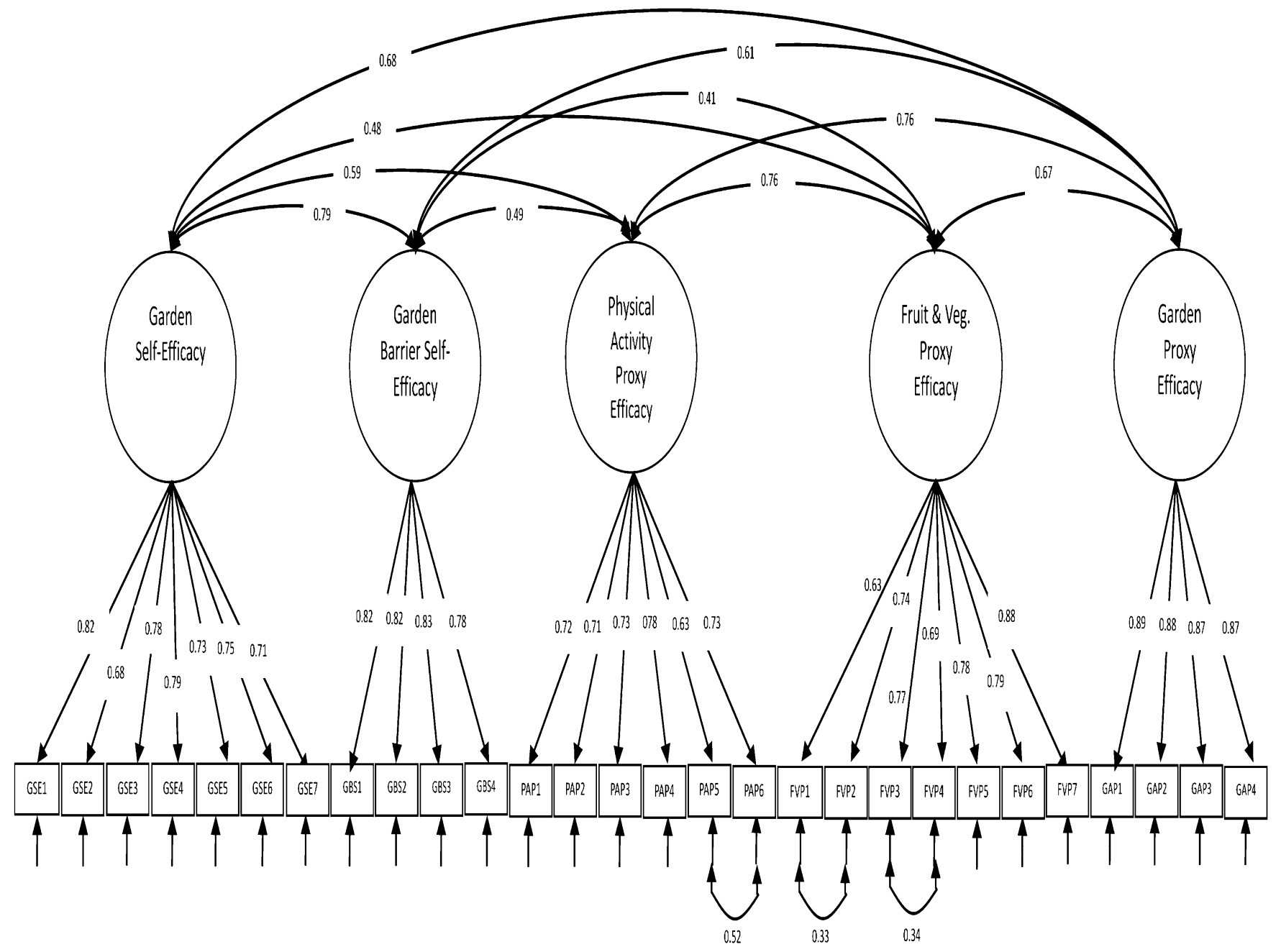

Fig. 1. Illustration of garden self-efficacy, garden barrier self-efficacy, parent proxy efficacy for physical activity, parent proxy efficacy for fruit and vegetable consumption, and parent proxy efficacy for gardening. Questionnaire items are depicted in boxes below the associated construct, specifically garden self-efficacy includes items GSE1-GSE7; garden barrier self-efficacy includes items GBS1-GBS4; physical activity proxy efficacy includes items PAP1-PAP6; fruit and vegetable proxy efficacy includes items FVP1FVP7; and parent proxy efficacy for gardening includes items GAP1-GAP4. Each questionnaire item is linked to its associated construct with a unidirectional error that provides the correlation between each item and the identified construct (i.e., factor loading). Correlations between theoretical constructs and certain item errors are depicted with two-directional, curved errors.

to the exercise domain, self-efficacy was found to represent two broad categories, task and regulatory. The task-related component of self-efficacy is assessed with questions targeting children's belief in their ability to perform certain attributes of a specific behavior. For physical activity, task relevant items commonly refer to prescribed intensity, frequency, and duration (Ryan and Dzewaltowski, 2002). Fruit and vegetable taskrelated self-efficacy has also been assessed among children, with items targeting children's confidence to eat specific amounts (i.e., servings) of fruits and vegetables (Geller et al., 2009; Geller and Dzewaltowski, $2010 \mathrm{a}, 2010 \mathrm{~b}$ ). These previous applications of task self-efficacy parallel the current garden self-efficacy construct, such that factor items captured children's self-efficacy to accomplish certain tasks that are specific to successful gardening. For example, items targeted children's confidence in their ability to "plant a seed," "water a garden," "find a place to garden," "plan a garden," "weed a garden," etc. The garden barrier self-efficacy can be compared with the regulatory component of self-efficacy, which has been referred to as one's perceived ability to manage difficulties inherent to the specified behavior (Ryan and Dzewaltowski, 2002). Regulatory self-efficacy has been commonly measured as one's confidence to persist in the face of behavior-specific barriers and has been measured with high validity and reliability in the physical activity context (Dzewaltowski et al., 2010; Ryan and Dzewaltowski, 2002). The illuminating garden barrier self-efficacy construct directly corresponds to physical activity measures, capturing children's confidence to garden in the face of similar barriers: "no matter how busy you are," "how tired you are," "if it is hot or cold outside," and "if you have a lot of homework."

Next, children's garden selfefficacy was revealed as a separate construct from parent-directed garden proxy efficacy, which parallels theory and similar research. Supporting Bandura (2001), self-efficacy can be assessed as a one-dimensional construct that is independent of proxy efficacy. Although the current study 
Table 2. Consistency tests for garden self-efficacy, garden barrier self-efficacy, parent proxy efficacy for physical activity, parent proxy efficacy for fruit and vegetable consumption, and parent proxy efficacy for gardening to identify potential bias across elementary-aged child subgroups based on gender, grade level, and weight status.

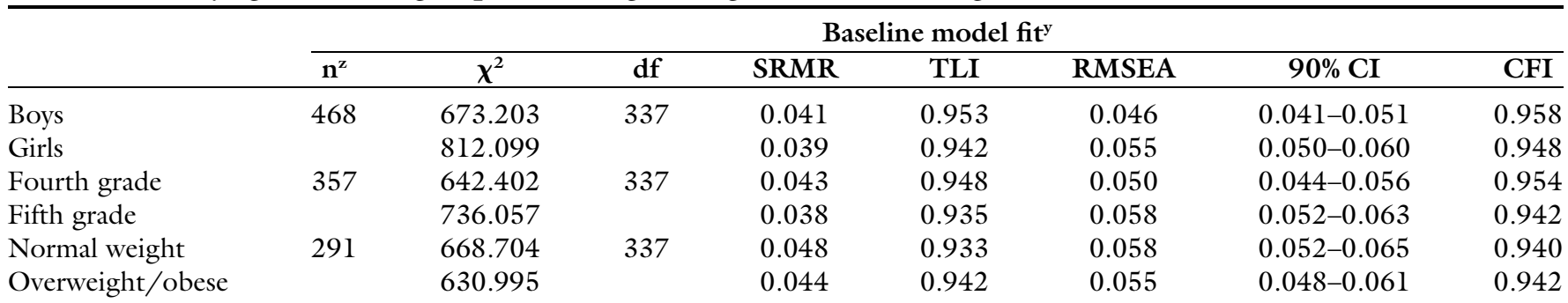

Measurement invariance

\begin{tabular}{|c|c|c|c|c|c|c|c|c|}
\hline$\chi^{2}$ & $\mathrm{df}$ & SRMR & & TLI & RMSEA & $90 \% \mathrm{CI}$ & CFI & $\Delta \mathrm{CFI}$ \\
\hline Model one ${ }^{\mathrm{x}}$ & 1572.889 & 720 & 0.042 & 0.948 & 0.050 & $0.047-0.054$ & 0.950 & 0.000 \\
\hline Model two ${ }^{w}$ & 1550.796 & 697 & 0.042 & 0.946 & 0.051 & $0.048-0.055$ & 0.950 & \\
\hline & & & & & rade level & & & \\
\hline & & & & & ight status & & & \\
\hline Model one & 1344.194 & 720 & 0.049 & 0.938 & 0.055 & $0.050-0.059$ & 0.941 & 0.000 \\
\hline Model two & 1323.118 & 697 & 0.046 & 0.936 & 0.056 & $0.051-0.060$ & 0.941 & \\
\hline
\end{tabular}

${ }^{2}$ Equal selection of subgroups selected randomly.

${ }^{\mathrm{y}} \chi^{2}=$ chi square value, SRMR $=$ standardized root mean residual (should be $\leq 0.08$ ), TLI $=$ Tucker-Lewis index (should be $\geq 0.95$ ), RMSEA $=$ root mean square error of approximation ( should be $\leq 0.05$ with $P<0.10$ ), $90 \% \mathrm{CI}=90 \% \mathrm{RMSEA}$ confidence interval, $\mathrm{CFI}=$ comparative fit index $($ should be $\geq 0.90$ ), $\Delta \mathrm{CFI}=$ change in CFI

xTested equality of the theorized factor structure $(\Delta \mathrm{CFI}$ should be $\leq 0.01)$.

wTested equality of item-to-factor loadings and item variances $(\Delta$ CFI should be $\leq 0.01)$

is the first garden-specific examination, valid assessment of self-efficacy and proxy efficacy as separate constructs has been previously demonstrated in similar contexts. For instance, research reported distinction between children's physical activity self-efficacy and proxy efficacy (Geller and Dzewaltowski, 2010a; Ryan and Dzewaltowski, 2002), which has been replicated relative to children's fruit and vegetable consumption (Geller et al., 2009; Geller and Dzewaltowski, 2010b).

Third, findings found that children's parent-directed proxy efficacy was measured distinctly based on three related contexts, which supports similar research. Although largely overlooked in extant research, proxy efficacy may be a critical factor to consider in the prevention of childhood obesity. Empowering youth with the skills and confidence to request opportunities for healthy behavior (i.e., proxy efficacy) may facilitate children's adoption of these behaviors. Youth are at the mercy of the authority figures who rule their surrounding environments and filter health-related opportunities. The current researchers believe proxy efficacy is an effective vehicle to behavioral promotion within these environments, with validated measurement scales relevant to multiple health behaviors. There is some intervention research documenting successful promotion of proxy efficacy to increase children's physical activity and related opportunities (Dzewaltowski et al., 2002, 2009). And a recent examination has documented a novel understanding of the mechanisms to increase children's fruit and vegetable proxy efficacy (Middlestadt et al., 2012). Similar research has targeted constructs comparable to proxy efficacy, targeting children's asking efficacy (i.e., confidence in behaviors that successfully elicit opportunities) and actual asking behavior (Baranowski et al., 2008; Buijzen and Valkenburg, 2008; Heim et al., 2009; Resnicow et al., 1997; Ryan and Dzewaltowski, 2002).

Current findings support comparable single behavior examinations and are novel in the investigation of proxy efficacy measurement scales relevant to multiple health-related behaviors. For example, parent-directed proxy efficacy for fruit and vegetable consumption has demonstrated strong factorial and criterion validity in previous examinations among youth populations (Geller et al., 2009; Geller and Dzewaltowski, $2010 \mathrm{a}, 2010 \mathrm{~b}$ ), with similar reports in the physical activity domain (Dzewaltowski et al., 2007, 2009, 2010). Multiple health-risk behaviors among youth are shown to cluster or cooccur (Alamian and Paradis, 2009; Spring et al., 2012), and this cooccurrence has been documented as the leading contributor to mortality (Berrigan et al., 2003) and health-related costs (Edington et al., 1997; Prochaska et al., 2008). The current is a novel and holistic examination of a measurement model that includes distinct, but related multiple health behaviors.

Fourth, findings demonstrated invariance of measurement scales across gender, grade level, and weight status, indicating established measures generalize consistently to similar subgroups. These results support previous research, reporting invariance of self-efficacy and proxy efficacy measurement scales. Specifically, physical activity self-efficacy has been reported 
Table 3. Criterion validity examination of garden self-efficacy, garden barrier self-efficacy, parent proxy efficacy for physical activity, parent proxy efficacy for fruit and vegetable consumption, and parent proxy efficacy for gardening, which included examination of potential differences in construct mean scores between subgroups based on gender, grade level, and weight status. Both unadjusted (i.e., crude) models and adjusted models are provided, with adjusted models including the following confounding variables: participating school site and child ethnicity (i.e., Caucasian, non-Hispanic, or ethnically diverse).

\begin{tabular}{|c|c|c|c|c|}
\hline \multirow[b]{3}{*}{ Factors } & \multicolumn{4}{|c|}{ Total sample $(n=969)$} \\
\hline & \multicolumn{2}{|c|}{ Unadjusted $^{\mathrm{z}}$} & \multicolumn{2}{|c|}{ Adjusted $^{\mathrm{z}}$} \\
\hline & Mean & SE & Mean & SE \\
\hline Garden barrier self-efficacy & 2.395 & 0.057 & 2.397 & 0.057 \\
\hline Physical activity proxy efficacy from parent & 3.413 & 0.047 & 3.416 & 0.047 \\
\hline Fruit and vegetable proxy efficacy from parent & 3.709 & 0.048 & 3.712 & 0.047 \\
\hline
\end{tabular}

Factor differences between males $(n=467)$ and females $(n=502)$

\begin{tabular}{|c|c|c|c|c|c|c|c|c|c|c|c|c|}
\hline & \multicolumn{6}{|c|}{ Unadjusted } & \multicolumn{6}{|c|}{ Adjusted } \\
\hline & \multicolumn{2}{|c|}{ Male } & \multicolumn{2}{|c|}{ Female } & \multirow[b]{2}{*}{$P$} & \multirow[b]{2}{*}{$\eta_{p}^{2}$} & \multicolumn{2}{|c|}{ Male } & \multicolumn{2}{|c|}{ Female } & \multirow[b]{2}{*}{$P$} & \multirow[b]{2}{*}{$\eta_{p}^{2}$} \\
\hline & Mean & SE & Mean & SE & & & Mean & SE & Mean & SE & & \\
\hline $\mathrm{GSE}^{\mathrm{z}}$ & $3.008 \mathrm{a}^{\mathrm{y}}$ & 0.071 & $3.548 \mathrm{~b}$ & 0.068 & 0.000 & 0.030 & $3.020 \mathrm{a}$ & 0.071 & $3.542 \mathrm{~b}$ & 0.067 & 0.000 & 0.029 \\
\hline GBS & $2.121 \mathrm{a}$ & 0.083 & $2.668 \mathrm{~b}$ & 0.079 & 0.000 & 0.023 & $2.131 \mathrm{a}$ & 0.083 & $2.663 \mathrm{~b}$ & 0.078 & 0.000 & 0.022 \\
\hline PAP & $3.331 \mathrm{a}$ & 0.069 & $3.495 \mathrm{a}$ & 0.065 & 0.083 & 0.003 & $3.341 \mathrm{a}$ & 0.068 & $3.491 \mathrm{a}$ & 0.065 & 0.117 & 0.003 \\
\hline FVP & $3.488 \mathrm{a}$ & 0.069 & $3.930 \mathrm{~b}$ & 0.066 & 0.000 & 0.022 & $3.499 \mathrm{a}$ & 0.069 & $3.924 \mathrm{~b}$ & 0.065 & 0.000 & 0.020 \\
\hline GAP & $2.711 \mathrm{a}$ & 0.089 & $3.388 \mathrm{~b}$ & 0.084 & 0.000 & 0.031 & $2.724 \mathrm{a}$ & 0.088 & $3.382 \mathrm{~b}$ & 0.083 & 0.000 & 0.029 \\
\hline
\end{tabular}

Factor differences between fourth graders $(n=611)$ and fifth graders $(n=358)$

\begin{tabular}{|c|c|c|c|c|c|c|c|c|c|c|c|c|}
\hline \multirow[b]{3}{*}{ GSE } & \multicolumn{6}{|c|}{ Unadjusted } & \multicolumn{6}{|c|}{ Adjusted } \\
\hline & \multicolumn{2}{|c|}{ Fourth grade } & \multicolumn{2}{|c|}{ Fifth grade } & \multirow[b]{2}{*}{0.957} & \multirow[b]{2}{*}{0.000} & \multicolumn{2}{|c|}{ Fourth grade } & \multicolumn{2}{|c|}{ Fifth grade } & \multirow[b]{2}{*}{0.644} & \multirow[b]{2}{*}{0.000} \\
\hline & $3.281 \mathrm{a}$ & 0.061 & $3.275 \mathrm{a}$ & 0.077 & & & $3.294 \mathrm{a}$ & 0.060 & $3.268 \mathrm{a}$ & 0.076 & & \\
\hline PAP & $3.358 \mathrm{a}$ & 0.059 & $3.468 \mathrm{a}$ & 0.074 & 0.244 & 0.001 & $3.369 \mathrm{a}$ & 0.058 & $3.463 \mathrm{a}$ & 0.074 & 0.394 & 0.001 \\
\hline FVP & $3.654 \mathrm{a}$ & 0.059 & $3.763 \mathrm{a}$ & 0.075 & 0.253 & 0.001 & $3.667 \mathrm{a}$ & 0.059 & $3.756 \mathrm{a}$ & 0.074 & 0.443 & 0.001 \\
\hline GAP & $3.024 \mathrm{a}$ & 0.076 & $3.075 \mathrm{a}$ & 0.096 & 0.674 & 0.000 & $3.039 \mathrm{a}$ & 0.075 & $3.067 \mathrm{a}$ & 0.095 & 0.902 & 0.000 \\
\hline
\end{tabular}

Factor differences between normal weight children $(n=678)$ and those at-risk for overweight/obesity $(n=291)$

\begin{tabular}{|c|c|c|c|c|c|c|c|c|c|c|c|c|}
\hline \multirow[b]{3}{*}{ GSE } & \multicolumn{6}{|c|}{ Unadjusted } & \multicolumn{6}{|c|}{ Adjusted } \\
\hline & \multicolumn{2}{|c|}{ Normal } & \multicolumn{2}{|c|}{ At-risk } & \multirow[b]{2}{*}{0.507} & \multirow[b]{2}{*}{0.000} & \multicolumn{2}{|c|}{ Normal } & \multicolumn{2}{|c|}{ At-risk } & \multirow[b]{2}{*}{0.284} & \multirow[b]{2}{*}{0.001} \\
\hline & $3.245 \mathrm{a}$ & 0.055 & $3.311 \mathrm{a}$ & 0.082 & & & $3.231 \mathrm{a}$ & 0.054 & $3.331 \mathrm{a}$ & 0.081 & & \\
\hline GBS & $2.337 \mathrm{a}$ & 0.064 & $2.453 \mathrm{a}$ & 0.095 & 0.312 & 0.001 & $2.326 \mathrm{a}$ & 0.064 & $2.468 \mathrm{a}$ & 0.095 & 0.204 & 0.002 \\
\hline PAP & $3.457 \mathrm{a}$ & 0.053 & $3.370 \mathrm{a}$ & 0.079 & 0.359 & 0.001 & $3.445 \mathrm{a}$ & 0.052 & $3.387 \mathrm{a}$ & 0.078 & 0.565 & 0.000 \\
\hline FVP & $3.709 \mathrm{a}$ & 0.053 & $3.709 \mathrm{a}$ & 0.082 & 0.999 & 0.000 & $3.695 \mathrm{a}$ & 0.053 & $3.728 \mathrm{a}$ & 0.079 & 0.703 & 0.000 \\
\hline GAP & $3.116 \mathrm{a}$ & 0.068 & $2.984 \mathrm{a}$ & 0.102 & 0.280 & 0.001 & $3.100 \mathrm{a}$ & 0.068 & $3.005 \mathrm{a}$ & 0.101 & 0.484 & 0.001 \\
\hline
\end{tabular}

${ }^{2}$ Unadjusted $=$ no confounding variables included, adjusted $=$ confounding variables are included, GSE $=$ garden self-efficacy, GBE $=$ garden barrier self-efficacy, PAP $=$ physical activity proxy efficacy from parent, $\mathrm{FVP}=$ fruit and vegetable self-efficacy, GAP $=$ garden proxy efficacy from parent, $\eta_{\mathrm{p}}{ }^{2}=$ partial eta squared effect size.

yAny row mean within either the unadjusted or adjusted column not followed by the same letter are significantly different at $P<0.05$.

invariant across multiple subgroups (Dishman et al., 2002; Dzewaltowski et al., 2010; Martin and McCaughtry, 2008). Results of invariant fruit and vegetable self-efficacy and proxy efficacy measurement scales also supports previous research among youth populations (Geller and Dzewaltowski, 2010a, 2010b). However, to our knowledge, the current study is the first to establish multigroup invariance for children's garden self-efficacy, garden barrier self-efficacy, and parentdirected proxy efficacy for physical activity and gardening opportunities.

Finally, measurement scale factor scores were used to detect gender differences in self-efficacy and proxy efficacy and supported appropriate criterion validity. Results demonstrated females had higher fruit and vegetable proxy efficacy compared with male children; hence, females were more confident they could successfully request fruit and vegetable availability from their parent. This finding differs from a previous examination among elementary-age children, reporting no gender differences in fruit and vegetable consumption proxy efficacy (Geller and Dzewaltowski, 2010a). One explanation for this contradiction may be due to the larger sample size included in the current analysis; additional research is warranted. If current results are supported, females' higher proxy efficacy may be contributing to reports of higher fruit and vegetable consumption among female children compared with males (Bere et al., 2007). Similarly, females were higher than males in garden selfefficacy and garden proxy efficacy; however, this is the first examination of these constructs to date, inhibiting research comparison. Finally, no gender differences were found in children's physical activity proxy efficacy, which supports a previous examination among elementary-aged children (Dzewaltowski et al., 2010). 


\section{Conclusion}

The current measures of self-efficacy and proxy efficacy across multiple health-related contexts demonstrated acceptable factorial validity, reliability, and criterion validity among elementary-age children. Given the strong potential of children's gardening in the prevention of obesity (Heim et al., 2009), additional research is needed to better understand the mediators underlying healthy behavior adoption within this context. Interventions may be able to reach parents by using youth proxy efficacy as a vehicle to promote healthy changes to obesityrelated behaviors, and study outcomes include valid measures for this purpose. Future investigations are required to determine if current constructs are central in the causal processes determining children's healthy behavior adoption and ultimate reduction in obesity risk. Future interventions should consider the distinction between self-efficacy and proxy efficacy constructs, as well distinction between proxy efficacy across gardening, physical activity, and fruit and vegetable contexts. And although additional research is warranted, the lower self-efficacy and proxy efficacy found among males should be considered during health promotion within gardening and fruit and vegetable contexts.

A number of study limitations are noteworthy. To begin, the sample may not represent the national population of elementary-age children. Although the sample did include children from ethnically diverse populations, a larger number within each diverse subgroup is needed to conduct appropriate tests of measurement invariance. Likewise, invariance tests were limited due to unavailable information about participants' socioeconomic status. Future research testing these efficacy constructs in more diverse samples and across varying age groups is needed. Finally, analyses relied on self-report data, which can result in numerous biases (e.g., social desirability bias, unwillingness to be truthful, and/or misunderstanding). Study strengths are also noted. The current study extends understanding of self-efficacy and proxy efficacy among children within the novel and promising garden context. Also, the evaluated measurement model is the first to examine proxy efficacy across multiple health behaviors.
There is limited research to date investigating efficacy constructs related to gardening behaviors and fewer evaluations of the representative measurement models; results offer a reliable and valid measurement tool with expected application in future research.

\section{Literature cited}

Alamian, A. and G. Paradis. 2009. Clustering of chronic disease behavioral risk factors in Canadian children and adolescents. Prev. Med. 48(5):493-499.

Bandura, A. 1986. Social foundations of thought and action: A cognitive social theory. Prentice Hall, Englewood Cliffs, NJ.

Bandura, A. 1997. Self-efficacy: The exercise of control. Freeman, New York, NY.

Bandura, A. 2001. Social cognitive theory: An agentic perspective. Annu. Rev. Psychol. 52(1):1-26.

Baranowski, T., K. Watson, M. Missaghian, A. Broadfoot, K. Cullen, T. Nicklas, J. Fisher, J. Baranowski, and S. O'Donnell. 2008. Social support is a primary influence on home fruit, $100 \%$ juice, and vegetable availability. J. Amer. Dietetic Assn. 108(7): 1231-1235.

Bentler, P.M. 1990. Comparative fit indexes in structural models. Psychol. Bull. 107(2):238-246.

Bere, E., J. Brug, and K.I. Klepp. 2007. Why do boys eat less fruit and vegetables than girls? Public Health Nutr. 11(3): 321-325.

Berrigan, D., K. Dodd, R.P. Troiano, S.M. Krebs-Smith, and R.B. Barbash. 2003. Patterns of health behavior in U.S. adults. Prev. Med. 36(5):615-623.

Bollen, K.A. 1989. Structural equations with latent variables. Wiley, New York, NY.

Brown, T.A. 2006. Confirmatory factor analysis for applied research. Guilford Press, London, UK/New York, NY.

Brown, H., C. Hume, N. Pearson, and J. Salmon. 2013. A systematic review of intervention effects on potential mediators of children's physical activity. BioMed Central Public Health 13(1):165-174.

Browne, M.W. and R. Cudeck. 1993. Alternative ways of assessing model fit, $\mathrm{p}$. 136-162. In: K.A. Bollen and J.S. Long (eds.). Testing structural equation models. Sage, Newbury Park, CA.

Buijzen, M. and P.M. Valkenburg. 2008. Observing purchase-related parent-child communication in retail environments: A developmental and socialization perspective. Hum. Commun. Res. 34(1):50-69.
Cattell, R.B. 1966. The scree test for the number of factors. Multivariate Behav. Res. 1(2):245-276.

Cheung, G.W. and R.B. Rensvold. 2002. Evaluating goodness-of-fit indexes for testing measurement invariance. Struct. Equ. Modeling 9(2):233-255.

Daniels, S.R. 2006. The consequences of childhood overweight and obesity. Future Child. 16(1):47-67.

Dishman, R.K., R.W. Motl, R.P. Saunders, M. Dowda, G. Felton, D.S. Ward, and R.R. Pate. 2002. Factorial invariance and latent mean structure of questionnaires measuring social-cognitive determinants of physical activity among black and white adolescent girls. Prev. Med. 34(1):100-108.

Domenghini, C., C. Shoemaker, M. Bopp, T. Hastmann, and D.A. Dzewaltowski. 2011. The use of social ecological theory to develop and implement an after-school garden club curriculum for overweight and obesity prevention. HortScience 46:S244 (abstr.).

Draper, C. and D. Freedman. 2010. Review and analysis of the benefits, purposes, and motivations associated with community gardening in the U.S. J. Community Pract. 18(4):458-492.

Dzewaltowski, D., P.A. Estabrooks, and J.A. Johnson. 2002. Healthy Youth Places promoting nutrition and physical activity. Health Educ. Res. 17:541-551.

Dzewaltowski, D.A., P.A. Estabrooks, G. Welk, J. Hill, G. Milliken, K. Karteroliotis, and J.A. Johnston. 2009. Healthy youth places: A randomized controlled trial to determine the effectiveness of facilitating adult and youth leaders to promote physical activity and fruit and vegetable consumption in middle schools. Health Educ. Behav. 36(3):583-600.

Dzewaltowski, D.A., K.S. Geller, R.R. Rosenkranz, and K. Karteroliotis. 2010. Children's self-efficacy and proxy efficacy for after-school physical activity. Psychol. Sport Exerc. 11(2):100-106.

Dzewaltowski, D.A., K. Karteroliotis, G. Welk, J.A. Johnston, D. Nyaronga, and P.A. Estabrooks. 2007. Measurement of self-efficacy and proxy efficacy for middle school youth physical activity. J. Sport Exerc. Psychol. 29:310-332.

Edington, D.W., L.T.C. Yen, and P. Witting. 1997. The financial impact of changes in personal health practices. J. Occup. Environ. Med. 39(11):1037-1046.

Evans, A., N. Ranjit, R. Rutledge, J. Medina, R. Jennings, A. Smiley, M. Stigler, and D. Hoelscher. 2012. Exposure to multiple components of a garden-based 
intervention for middle school students increases fruit and vegetable consumption. Health Promot. Pract. 13(5):608-616.

Geller, K.S. and D.A. Dzewaltowski. 2009. Longitudinal and cross-sectional influences on youth fruit and vegetable consumption. Nutr. Rev. 67(2):65-76.

Geller, K.S. and D.A. Dzewaltowski. 2010a. Examining elementary schoolaged children's self-efficacy and proxy efficacy for fruit and vegetable consumption. Health Educ. Behav. 37:465-478.

Geller, K.S. and D.A. Dzewaltowski. $2010 \mathrm{~b}$. Youth proxy efficacy for fruit and vegetable availability varies by gender and socio-economic status. Public Health Nutr. 13(6):843-851.

Geller, K.S., D.A. Dzewaltowski, R.R. Rosenkranz, and K. Karteroliotis. 2009. Measuring children's self-efficacy and proxy efficacy related to fruit and vegetable consumption. J. Sch. Health 79(2): 51-57.

Golan, M. and S. Crow. 2004. Parents are key players in the prevention and treatment of weight-related problems. Nutr. Rev. 62(1):39-50.

Gorsuch, R.L. 1983. Factor analysis. 2nd ed. Lawrence Erlbaum Assoc., Hillsdale, NJ.

Guenther, P.M., K.W. Dodd, J. Reedy, and S.M. Krebs-Smith. 2006. Most Americans eat much less than recommended amounts of fruits and vegetables. J. Amer. Dietetic Assn. 106(9):1371-1379.

Heim, S., J. Stang, and M. Ireland. 2009. A garden pilot project enhances fruit and vegetable consumption among children. J. Amer. Dietetic Assn. 109(7):1220-1226.

Janssen, I., P.T. Katzmarzyk, W.F. Boyce, C. Vereecken, C. Mulvihill, C. Roberts, C. Currie, and W. Pickett. 2005. Comparison of overweight and obesity prevalence in school-aged youth from 34 countries and their relationships with physical activity and dietary patterns. Obes. Rev. 6(2):123-132.

Joreskog, K.G. 1993. Testing structural equation models, p. 294-316. In: K.A. Bollen and J.S. Long (eds.). Testing structural equation models. Sage, Newbury Park, CA.

Kaiser, H. 1961. A note on Guttman's lower bound for the number of common factors. Multivariate Behav. Res. 14(1):249-276.

Langellotto, G. and A. Gupta. 2012. Gardening increases vegetable consumption in school-aged children: A metaanalytical synthesis. HortTechnology 22: 430-445.

Lubans, D.R., C. Foster, and S.J. Biddle. 2008. A review of mediators of behavior in interventions to promote physical ac- tivity among children and adolescents. Prev. Med. 47(5):463-470.

Martin, J.J. and N. McCaughtry. 2008. Using social cognitive theory to predict physical activity in inner-city African American school children. J. Sport Exerc. Psychol. 30(4):378-391.

Middlestadt, S.E., A.M. Lederer, N.K. Smith, D. Doss, C.L. Hung, L.D. Stevenson, and A.D. Fly. 2012. Determinants of middle-school students asking parents for fruits and vegetables: A theory-based salient belief elicitation. Public Health Nutr. 16(11):1971-1978.

Morris, J. and S. Zidenberg-Cherr. 2002. Garden-enhanced nutrition curriculum improves fourth-grade school children's knowledge of nutrition and preferences for some vegetables. J. Amer. Dietetic Assn. 102(1):91-93.

Nicklas, T.A., S.J. Yang, T. Baranowski, I. Zakeri, and G. Berenson. 2003. Eating patterns and obesity in children: The Bogalusa heart study. Amer. J. Prev. Med. 25(1):9-16.

Ogden, C.L., M.D. Carroll, B.K. Kit, and K.M. Flegal. 2012. Prevalence of obesity and trends in body mass index among US children and adolescents, 1999-2010. J. Amer. Dietetic Assn. 307(5):483-490.

Parmer, S.M., J. Salisbury-Glennon, D. Shannon, and B. Struempler. 2009. School gardens: An experiential learning approach for a nutrition education program to increase fruit and vegetable knowledge, preference, and consumption among second-grade students. J. Nutr. Educ. Behav. 41(3):212-217.

Perez-Lizaur, A.B., M. Kaufer-Horwitz, and M. Plazas. 2008. Environmental and personal correlates of fruit and vegetable consumption in low income, urban Mexican children. J. Hum. Nutr. Diet. 21(1):63-71.

O'Brien, S.A. and C.A. Shoemaker. 2006. An after-school gardening club to promote fruit and vegetable consumption among fourth grade students: The assessment of social cognitive theory constructs. HortTechnology 16:24-29.

Poston, S.A., C.A. Shoemaker, and D.A. Dzewaltowski. 2005. A comparison of a gardening and nutrition program with a standard nutrition program in an out-of-school setting. HortTechnology 15:463-467.

Prochaska, J.J., B. Spring, and C.R. Nigg. 2008. Multiple health behavior change research: An introduction and overview. Prev. Med. 46(3):181-188.

Ratcliffe, M.M., K.A. Merrigan, B.L. Rogers, and J.P. Goldberg. 2011. The effects of school garden experiences on middle school-aged students' knowledge, attitudes, and behaviors associated with vegetable consumption. Health Promot. Pract. 12(1):36-43.

Resnicow, K., M. Davis-Hearn, M. Smith, T. Baranowski, L.S. Lin, J. Baranowski, C. Doyle, and D.T. Wang. 1997. Socialcognitive predictors of fruit and vegetable intake in children. Health Psychol. 16(3): 272-276.

Reynolds, K.D., A.L. Yaroch, F.A. Franklin, and J. Maloy. 2002. Testing mediating variables in a school-based nutrition intervention program. Health Psychol. 21(1):51-60.

Ryan, G.J. and D.A. Dzewaltowski. 2002. Comparing the relationships between different types of self-efficacy and physical activity in youth. Health Educ. Behav. 29(4):491-504.

Saunders, R.P., R.R. Pate, G. Felton, M. Dowda, M.C. Weinrich, D.S. Ward, M.A. Parsons, and T. Baranowski. 1997. Development of questionnaires to measure psychosocial influences on children's physical activity. Prev. Med. 26(2):241-247.

Sharma, M., D.I. Wagner, and J. Wilkerson. 2005. Predicting childhood obesity prevention behaviors using social cognitive theory. Intl. Q. Community Health Educ. 24(3):191-203.

Shoemaker, C., C. Domenghini, G. Milliken, G. Welk, and D.A. Dzewaltowski. 2013. Integrating schools, community, and family to effect sedentary behavior, fruit and vegetable consumption and physical activity through gardening. HortScience 48:S241 (abstr.).

Sisson, S.B., S.T. Broyles, B.L. Baker, and P. T. Katzmarzyk. 2011. Television, reading, and computer time: Correlates of school-day leisure-time sedentary behavior and relationship with overweight in children in the U.S. J. Phys. Act. Health 8(2):S188-S197.

Spring, B., A.C. Moller, and M.J. Coons. 2012. Multiple health behaviours: Overview and implications. J. Public Health 34 (Suppl 1):i3-il 0 .

Troiano, R.P., D. Berrigan, K.W. Dodd, L.C. Masse, T. Tilert, and M. McDowell. 2008. Physical activity in the U.S. measured by accelerometer. Med. Sci. Sports Exerc. 40(1):181-188.

Wang, G. and W.H. Dietz. 2002. Economic burden of obesity in youths aged 6 to 17 years: 1979-1999. Pediatrics 109(5):E81-1.

White House Task Force on Childhood Obesity. 2010. Solving the problem of childhood obesity within a generation. White House Task Force on Childhood Obesity, Washington, DC. 